\title{
RANCANG BANGUN SISTEM INFORMASI ANALISIS KEPUASAN DALAM PROSES BELAJAR MENGAJAR DI SMA NEGERI 3 MATARAM MENGGUNAKAN METODE QUALITY FUNCTION DEPLOYMENT
}

\author{
(Design of Information System of Satisfaction and Learning Process Analysis in \\ Mataram Public High School 3 Using The Quality Function Deployment Method )
}

\author{
Wahda Farah Batari*, Budi Irmawati \\ Program Studi Teknik Informatika, Universitas Mataram \\ JI. Majapahit 62, Mataram, Lombok NTB, INDONESIA \\ Email:wahda0894@gmail.com, yzakodek@gmail.com
}

\begin{abstract}
Abstract- A senior high school is responsible to deliver competitive human resources. A high school that has good facilities are more popular and attractive for junior high school students. To evaluate the school quality of service, we build a system to analyze the students satisfaction about the learning process and services. To conduct the analysis, an information system was built to identify what components of the learning process needed to be improved. The method used is Quality Function Deployment (QFD) that clearly defines the needs and the expectations of students. The evaluation process was doing by asking students to fill out a satisfaction questionnaire through the system. To get the analysis continuously this evaluation process can be carried out annually at the end of each school year. By using this computerized system, the evaluation results are obtained faster and more accurate
\end{abstract}

Keywords: Quality Function Deployment, questioner, satisfaction analysis, QFD, expectations and perceptions

*Penulis Korespondensi

\section{Pendahuluan}

Dewasa ini perkembangan teknologi sangatlah pesat, terutama dalam bidang teknologi informasi. Teknologi informasi sangat membantu dalam membuat, mengubah, menyimpan mengkomunikasikan dan menyebar informasi. Pemanfaatan teknologi informasi juga berperan penting pada sekolah-sekolah yang menggunakan teknologi informasi, baik dalam belajar mengajar maupun dalam penyediaan jasa.

Sekolah Menengah Atas atau biasa disingkat SMA merupakan salah satu penyedia jasa yang melahirkan sumber daya manusia yang diharapkan mampu untuk berdaya saing. SMA yang menawarkan berbagai fasilitas yang baik menjadi salah satu alasan mengapa SMA tersebut lebih diminati oleh siswa-siswa lulusan SMP. Hal ini menyebabkan terjadinya persaingan yang ketat antar SMA. Karena adanya persaingan tersebut lembaga pendidikan dituntut untuk lebih memperhatikan mutu pendidikan agar dapat unggul dalam persaingan tersebut.

Untuk unggul dalam persaingan, pengelola lembaga pendidikan harus memperhatikan berbagai aspek yang mampu meningkatkan kualitas siswa. Untuk mengetahui kualitas layanan yang diberikan oleh sekolah saat ini, diperlukan sebuah sistem yang mampu menganalisa parameter kebutuhan siswa dalam hal mutu pendidikan. Untuk mewujudkan hal tersebut maka dipilih sebuah sekolah sebagai lokasi untuk melakukan penelitian mengenai analisis kepuasan proses belajar mengajar dan sekolah tersebut adalah SMA Negeri 3 Mataram. Sekolah tersebut memiliki sekitar 1500 siswa yang tersebar dalam beberapa jurusan. Dengan banyaknya siswa pada sekolah tersebut diperlukan sebuah sistem untuk menganalisis apakah pada sekolah tersebut kebutuhan siswa dalam hal pembelajaran telah terpenuhi dengan baik. Sebelumnya pada sekolah tersebut pernah dilakukan sebuah penelitian mengenai proses pembelajaran, akan tetapi penelitian yang dilakukan masih menggunakan metode manual yaitu dengan lembaran yang dibagikan ke siswa. Metode ini dirasa kurang efektif karena data yang didapat dari metode tersebut tidak terintegrasi dengan baik dan apabila ingin dilakukan analisis secara berkala akan menghabiskan banyak kertas dan kemungkinan 
terjadinya human error akan sangat besar. Oleh karena itu dibangun sebuah sistem informasi yang mampu mengidentifikasi apa saja yang perlu ditingkatkan pada proses belajar mengajar serta mampu memberikan data yang akurat. Untuk mencapai hal tersebut sistem yang digunakan harus menggunakan metode yang sesuai dengan keinginan dan kebutuhan siswa. Maka digunakan metode Quality Function Deployment (QFD) dimana metode tersebut mendefinisikan secara jelas kebutuhan dan harapan siswa dalam hal belajar mengajar dan mengevaluasi kemampuan sistem untuk memenuhi kebutuhan dan harapan. Dengan adanya sistem informasi analisis belajar mengajar siswa ini, akan sangat memungkinkan bila pihak sekolah ingin melakukan pengisian kuesioner pada setiap tahun ajaran baru. Hasil yang didapat juga akan lebih cepat dan akurat karena menggunakan sistem yang terintegrasi.

\section{TINJAUAN PUStaka}

Penelitian tentang penerapan metode Quality Function Deployment (QFD) pada rencana pengembangan sekolah (studi kasus di SMKN 2 Yogyakarta) telah berhasil dilakukan. Penelitian ini dilakukan untuk mengetahui pengaruh dari penerapan motode QFD sebagai sarana untuk meningkatkan keakuratan dan ketepatan dalam perencanaan pengembangan. Adapun kategori penerapan metode QFD pada rencana pengembangan sekolah bidang sarana dan prasarana serta pengelolaanya dikategorikan sangat baik dengan persentase 37\%, dikategorikan baik dengan persentase $63 \%$ dan dikategorikan cukup baik maupun tidak baik dengan persentase $0 \%[1]$.

Penelitian tentang penerapan metode QFD pada unit usaha dengan studi kasus pada SMKN 2 Yogyakarta berhasil dilakukan. Penelitian ini dilakukan untuk mengetahui sejauh mana metode QFD telah diterapkan pada unit usaha jurusan TKR dan TP di SMK Negeri 2 Yogyakarta. Tahapan pelaksanaan metode QFD yang telah dilaksanakan di unit usaha TKR dan TP adalah penjaminan kualitas jasa, menerima penilaian dari konsumen atas jasa, angket kebutuhan konsumen dan mengetahui prioritas kepentingan kebutuhan konsumen. Metode QFD pada jurusan TKR dikategorikan baik dengan persentase $50 \%$, dikategorikan sangat baik dengan persentase 33\%, dikategorikan cukup dengan persentase $17 \%$ dan dikategorikan tidak baik dengan persentase $0 \%$. Pada jurusan TP kategori metode QFD dikategorikan baik dengan persentase $55 \%$, dikategorikan sangat baik dengan persentase $18 \%$, dikategorikan cukup dengan persentase $17 \%$ dan dikategorikan tidak baik dengan persentase $0 \%[2]$.

Penelitian tentang kualitas pelayanan perpustakaan di perguruan tinggi menggunakan metode QFD dengan studi kasus di Unit Perpustakaan Pusat Universitas Muhammadyah Surakarta berhasil dilakukan. Pada penelitiannya dijelaskan bahwa pelayanan pada UPT Muhammadyah Surakarta harus lebih ditingkatkan, mengingat pentingnya sebuah informasi dalam kehidupan bermasyarakat. Dijelaskan juga bahwa sebuah perpustakaan seharusnya lebih memikat, cepat dan akurat, oleh karena itu orientasi layanan perpustakaan harus berdasarkan pada kebutuhan pengguna. Pelayanan pada perpustakaan juga seharusnya lebih ramah agar pelanggan dapat lebih nyaman saat melakukan interaksi dengan staf perpustakaan. Adapun hasil dari penelitian ini adalah terdapat beberapa atribut yang dianggap sangat penting oleh konsumen yaitu: kelengkapan buku, keamanan di loker, ruangan yang nyaman, komputer yang berfungsi dengan baik, kebersihan perpustakaan, fasilitas internet yang memadai, karyawan yang cakap penelusuran bahan pustaka tersedia di komputer sama dengan call number di rak dan penempatan bahan pustaka di rak sesuai dengan lokasi dan call number[3].

Penelitian tentang analisis kepuasan layanan administrasi akademik berbasis Importance Performance Analysis(IPA) dengan kasus pada Fakultas Teknik Universitas Mataram berhasil dilakukan. Pada penelitian ini menggunakan kuesioner online sebagai sarana untuk mahasiswa dalam menyampaikan pendapatnya mengenai layanan akademik pada Fakultas Teknik Universitas Mataram sudah memuaskan atau belum, di mana data yang terkumpul akan diolah menggunakan aplikasi berbasis website dan akan memiliki keluaran berupa grafik tingkat kepuasan mahasiswa yang terdiri dari grafik Fakultas dan masing-masing Jurusan/Program Studi[4].

Pada penelitian ini akan dilakukan pengujian apakah di Sekolah Menengah Atas (SMA) masih memiliki masalah atau kekurangan dalam proses belajar mengajar menggunakan metode QFD pada studi kasus SMA Negeri 3 Mataram. Adapun acuan dari penelitian ini adalah penelitian [1] yang melakukan pengujian untuk meningkatkan pengembangan SMK pada bidang sarana dan prasarana menggunakan metode QFD, tetapi terdapat perbedaan teknis yang dilakukan dalam pengujian ini yaitu dengan sistem online di mana pengguna dapat dengan langsung mengetahui hasilnya melalui web yang diakses, sedangkan pada penelitian tersebut proses yang 
dilakukan secara manual yaitu dengan membagikan kuesioner secara langsung.

Berdasarkan penelitian-penelitian yang telah dilakukan tersebut, dapat disimpulkan bahwa metode QFD cocok dalam melakukan analisa kepuasan pelanggan. QFD didesain untuk membantu para perencana agar dapat fokus pada karakteristik dari layanan yang ada berasal dari sudut pandang pelanggan. Oleh karena itu dibuat sebuah sistem informasiyangmenyediakan kuesioner online sebagai media untuk pelanggan dalam menyampaikan pendapat mengenai kepuasan mereka dalam proses belajar mengajar di SMA Negeri 3 Mataram. Data dari kuesioner akan dianalisis menggunakan metode QFD dan hasil akhirnya dituangkan dalam bentuk Matriks House of Quality.

\section{Metode Penelitian}

Metode penelitian terdiri dari beberapa bagian yaitu studi literatur, pengumpulan data, analisis sistem dan desain sistem, implementasi dan pengujian sistem serta hasil pengujian dan pembahasan yang dapat dilihat sebagai berikut:

\section{A. Studi Literatur}

Studi literatur dilakukan untuk menghimpun data atau sumber yang berkaitan dengan topik yang diangkat pada sebuah penelitian. Literatur yang digunakan pada penelitian ini adalah buku, jurnal, berbagai dokumentasi, dan pustaka yang mengambil semua data terkait dengan metode QFD.

\section{B. Pengumpulan Data}

Jenis dan sumber data yang dianalisis dalam penyusunan penelitian ini adalah

\section{B.1. Data primer}

Data Primer adalah data yang diperoleh dari wawancara pada pihak sekolah. Wawancara dilakukan secara lisan dalam pertemuan tatap muka secara individual. Pedoman wawancara yang digunakan dalam penelitian ini menggunakan pedoman wawancara terstruktur dan terbuka[5]. Wawancara dilakukan pada pihak sekolah mengenai mata pelajaran apa saja yang terdapat pada SMAN 3 Mataram dan bagaimana proses pembelajaran di sekolah tersebut

\section{B.2. Data sekunder}

Data sekunder adalah data yang didapat dari perpustakaan, buku dan jurnal[6]. Data yang didapat adalah seluruh data yang berkaitan dengan tahapan Metode QFD serta perhitungannya, sehingga mampu menghasilkan data hasil yang akurat.
Untuk mengukur ekspektasi / harapan layanan menggunakan lima skala penilaian yaitu[7]:

1. Skor 1 (Sangat Tidak Penting), jika tingkat harapan dari atribut layanan sangat tidak penting

2. Skor 2 (Tidak Penting), jika tingkat harapan dari atribut layanan tidak penting.

3. Skor 3 (Cukup Penting), jika tingkat harapan dari atribut layanan cukup penting.

4. Skor 4 (Penting), jika tingkat harapan dari atribut layanan penting.

5. Skor 5 (Sangat Penting), jika tingkat harapan dari atribut layanan sangat penting.

Sedangkan untuk mengukur tingkat persepsi layanan menggunakan lima skala penilaian yaitu [7]:

1. Skor 1 (Tidak Puas), jika merasa tidak puas dengan layanan yang diterima.

2. Skor 2 (Kurang Puas), jika merasa kurang puas dengan layanan yang diterima

3. Skor 3 (Cukup Puas), jika merasa cukup puas dengan layanan yang diterima.

4. Skor 4 (Puas), jika merasa puas dengan layanan yang diterima.

5. Skor 5 (Sangat Puas), jika merasa sangat puas dengan layanan yang diterima.

\section{Analisis Sistem}

Metode Quality Function Deployment (QFD) adalah suatu proses atau mekanisme terstruktur untuk menentukan kebutuhan pelanggan dan menerjemahkan kebutuhan-kebutuhan itu ke dalam kebutuhan teknis yang relevan, dimana masing-masing area fungsional dan level organisasi dapat mengerti dan bertindak[8].

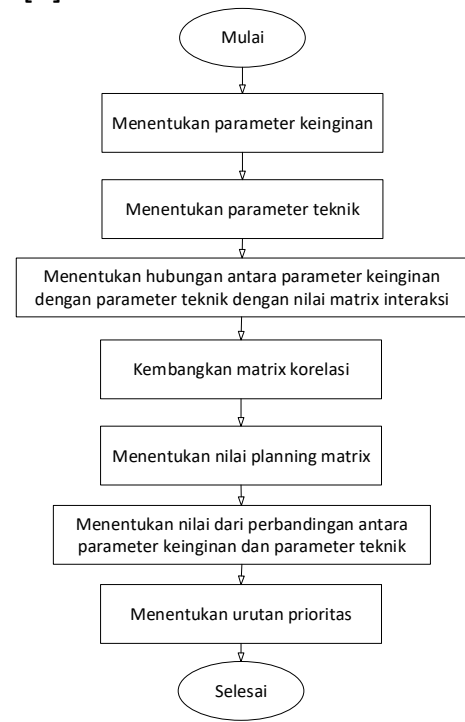

Gambar 1. Gambar 1 merupakan diagram alir metode Quality Function Deployment. 
Gambar 1 merupakan diagram alir metode QFD dimana gambar 1 merupakan urutan rancangan sistem yang diterapkan pada sistem informasi kepuasan yang telah dibuat.

Dalam pengimplementasiannya metode QFD akan menghasilkan matrix House of Quality yang nantinya akan menunjukkan hasil akhir dari metode Quality Function Deployment[9].

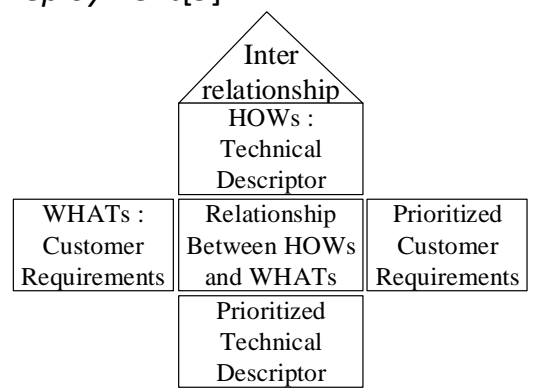

\section{Gambar 2. Matrix House of Quality}

Terdapat beberapa tahapan yang harus dilakukan untuk menghasilkan matrix House of Quality, yaitu[9]:

1. Menentukan Customer Requirements.

Daftar ini sering disebut sebagai WHATs yang dibutuhkan atau diharapkan pelanggan dari produk tertentu. Daftar kebutuhan pelanggan utama ini biasanya bersifat samar dan sangat umum. Menentukan kebutuhan yang dipentingkan konsumen (berupa data kualitatif) dan data ini diperoleh dari wawancara dan observasi terhadap konsumen. Dalam penyusunan kuesioner ini dilakukan tahap pertama dengan berdiskusi dan sharing dengan beberapa kelompok konsumen untuk mendapatkan input/masukan tentang keinginan para konsumen. Kemudian dari hasil diskusi dan wawancara langsung dengan para konsumen tersebut dapat diambil beberapa atribut.

2. Menentukan Technical Descriptor (Parameter Teknik)

Tujuan dari HOQ adalah merancang atau mengubah desain suatu produk dengan cara memenuhi atau melampaui harapan pelanggan. Kebutuhan dan harapan pelanggan dinyatakan dalam persyaratan pelanggan, tim penyusun QFD harus mengemukakan parameter teknik yang akan mempengaruhi satu atau lebih persyaratan pelanggan. Setiap parameter harus secara langsung mempengaruhi kebutuhan pelanggan dan dinyatakan dalam istilah terukur.

3. Mengembangkan Matriks Hubungan Antara(WHATs dan HOWs)

Langkah selanjutnya dalam membangun $\mathrm{HOQ}$ adalah membandingkan persyaratan pelanggan dan karakteristik teknik untuk menentukan hubungan masing-masing. Setiap kebutuhan pelanggan dapat mempengaruhi lebih dari satu parameter teknik yang dihubungkan dengan matriks hubungan. Matrix hubungan digunakan untuk mewakili secara grafis tingkat pengaruh antara masingmasing karakteristik teknik dan setiap kebutuhan pelanggan.

4. Kembangkan Matriks Korelasi (HOWs).

Bagian atas dari matriks $\mathrm{HOQ}$ disebut matriks korelasi yang digunakan untuk mengidentifikasi keterkaitan antara pasangan parameter teknik. Matriks korelasi memungkinkan pengguna untuk mengidentifikasi karakteristik teknik yang paling penting karena sering kali merupakan hasil dari persyaratan pelanggan yang saling bertentangan. Matriks korelasi menggambarkan hubungan dan ketergantungan antar respon teknis, sehingga bias dilihat apakah suatu respon teknis yang satu mempengaruhi respon teknis yang lain. Tetapi yang perlu diperhatikan adalah tidak seluruh respon teknis mempunyai hubungan satu per satu dengan respon teknis lainnya. Hubungan korelasi tersebut adalah:

4.1. Hubungan Kuat Positif (++)

Hubungan ini merupakan hubungan searah, yang terjadi apabila salah satu respon teknis mengalami peningkatan atau penurunan dan akan berpengaruh kuat pada peningkatan atau penurunan respon teknis lain yang terkait.

4.2. Hubungan Positif (+)

Hubungan ini terjadi apabila salah satu respon teknis mengalami peningkatan atau penurunan dan akan berpengaruh pada peningkatan atau penurunan 
respon teknis lain yang terkait. Hubungan ini juga merupakan hubungan searah.

4.3. Hubungan Negatif (-)

Hubungan ini terjadi pada kondisi berbanding terbalik, artinya apabila salah satu respon teknis mengalami peningkatan akan menyebabkan penurunan pada respon teknis lain yang terkait

4.4. Hubungan Kuat Negatif ( $\boldsymbol{\nabla}$ )

Hubungan ini terjadi pada kondisi yang sangat berbanding terbalik, artinya apabila salah satu respon teknis mengalami peningkatan akan berpengaruh kuat pada penurunan respon teknis lainnya.

5. Menentukan Nilai Planning Matrix

5.1. Menentukan derajat kepentingan .

Penentuan tingkat kepentingan konsumen digunakan untuk mengetahui sejauh mana konsumen memberikan penilaian atau harapan dari kebutuhan konsumen yang ada. Tingkat kepentingan dihitung dengan menggunakan Persamaan 1.

Derajat Kepentingan $=\sum_{i=1}^{n} D K_{i}$

dimana :

$D K_{i}=$ derajatkepentinganrespondenke-i

$\mathrm{n}=$ jumlah responden

5.2. Kinerja atribut .

Pengukuran tingkat kepuasan konsumen terhadap produk / jasa dimaksudkan untuk mengukur bagaimana tingkat kepuasan konsumen setelah pemakaian produk/jasa yang akan dianalisis. Tingkat kepuasan dihitung dengan menggunakan Persamaan 2.

dimana:

$$
\text { Kinerja }=\sum_{i=1}^{n} K_{i}
$$

$\mathrm{K}_{\mathrm{i}}=$ kepuasan responden

$\mathrm{n}=$ jumlah responden

5.3 Nilai target Atribut Jasa (goals).

Nilai target ini ditentukan oleh pihak institusi yang akan dianalisis dan menunjukkan nilai target yang akan dicapai untuk tiap kebutuhan konsumen

5.4 Menentukan Perbaikan

Rasio perbaikan yaitu perbandingan antara nilai target yang akan dicapai (goal) pihak institusi dengan tingkat kepuasan konsumen terhadap suatu produk/jasa. Dihitung dengan Persamaan 3.

Rasio Perbaikan $=\frac{\text { NilaiTarget }}{\text { Kinerja }}$

5.5 Menentukan Sales Point

Sales Point merupakan besaran yang mempengaruhi tingkat kepuasan mahasiswa sehingga nilaiSales Point pada masing-masing atribut menunjukkan pengaruh masing-masing terhadap kemampuan untuk memuaskan kepentingan mahasiswa. Nilai yang bisa dipakai adalah :

1 = Tanpa titik kepuasan

1.2 = Titik kepuasan menengah

$1.5=$ Titik kepuasan tinggi

5.6 Menentukan Bobot Atribut Jasa Bobot merupakan nilai keseluruhan dari data yang dimasukkan dalam planning matrix tiap kebutuhan konsumen untuk proses perbaikan selanjutnya dalam pengembangan produk/jasa. Nilai bobot dapat dihitung dengan Persamaan 4.

Bobot $=($ Derajat Kepentingan $) \times($ Rasio Perbaikan) $\mathrm{x}$ (Salespoint)

5.7 Menentukan Normalisasi Bobot Atribut Jasa.

Merupakan nilai dari Raw Weight yang dibuat dalam skala antara 0-1 atau dibuat dalam bentuk persentase. Dapat dihitung dengan Persamaan 5.

Normalisasi Bobot $=\frac{\text { Bobot }}{\text { TotalBobot }}$

6. Menentukan Nilai dari perbandingan antara parameter keinginan dan parameter teknik. Tahap ini berguna sebagai nilai pada masingmasing perbandingan yang akan digunakan dalam Matrix House of Quality. Adapun persamaan yang digunakan sebagai berikut: Bobot Interaksi $=$ Normalisasi bobot $\mathrm{x}$ 
nilai interaksi

(6)

7. Menentukan

atribut

prioritas

Tahap ini memiliki tiga bagian yaitu jumlah, persentase dan urutan prioritas. Jumlah memiliki persamaan sebagai berikut:

Jumlah $=\quad \sum_{i=1}^{n=23}$ Atribut $1+$ Atribut $2 \ldots+$ Atributn

Persentase memiliki persamaan sebagai berikut:

$$
\text { Persentase }=\frac{\text { Jumlah }}{\text { totaljumlah }} \times 100 \%
$$

Urutan Prioritas yang harus dibenahi ditentukan dari nilai persentase yang paling besar. Semakin tinggi nilai persentase maka atribut tersebut menjadi prioritas untuk ditingkatkan.

\section{Desain Sistem}

Tahap desain merupakan tahap perancangan sistem atau penggambaran tentang sistem yang akan dibuat. Pada tahap desain ini terdiri dari use case diagram, entity relatioship diagram, tabel database, class diagram, sequence diagram, activity diagram, antarmuka (interface) dan Quality Function Deployment (QFD).

D.1. Use Case Diagram Sistem Informasi Analisis Kepuasan Belajar Mengajar

Use case merupakan urutan kejadian yang menggambarkan interaksi antara user dengan sistem. Fungsionalitas sistem di definisikan ke dalam use case dari sudut eksternal sistem yang berguna untuk di uji kelayakan sistem[10]. Pada use case diagram Sistem analisis kepuasan yang ditujukan pada Gambar 3 memiliki tiga aktor yaitu admin, siswa dan wakil kepala sekolah dimana ketiga aktor melakukan login terlebih dahulu ke sistem untuk dapat melakukan operasi pada sistem. Admin dapat mengolah data mapel, user, parameter teknik, kelas, soal, dan interaksi soal parameter. Siswa dapat melakukan isi kuesioner dan wakil kepala sekolah dapat melihat hasil kuesioner siswa

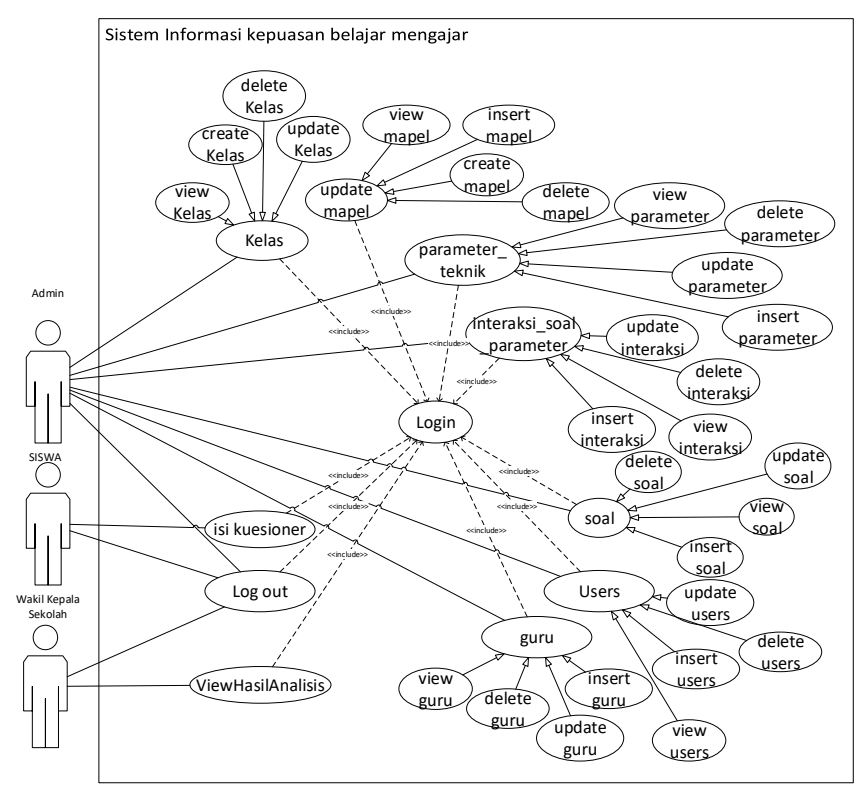

Gambar 3. Use Case Diagrampada sistem analisis kepuasan belajar mengajar

D.2. Entity Relation DiagramSistem Informasi Analisis Kepuasan Belajar Mengajar

ERD (Entity Relation Diagram) adalah cara untuk menggambarkan gambaran dari dunia nyata yang akan diterapkan pada suatu database sebuah sistem[10]. Diagram ER sistem analisis kepuasan belajar mengajar pada SMA Negeri 3 Mataram memiliki 8 entitas yaitu mapel, siswa, guru, kelas, pertanyaan, parameter teknik, wakasek dan admin serta memiliki 5 relasi.

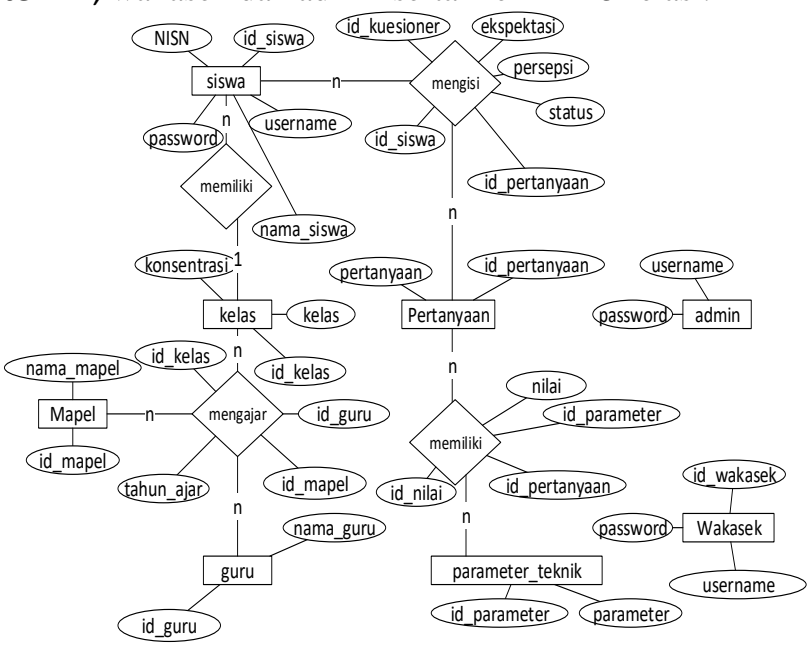

Gambar 4. Entity Relation Diagram pada sistem analisis kepuasan belajar mengajar

\section{D.3. Quality Function Deployment (QFD).}

Pada sistem informasi analisis kepuasan belajar mengajar pada SMA Negeri 3 Mataram terdapat 3 user yang terlibat yaitu admin, siswa dan wakil kepala sekolah. User pertama yaitu admin yang dapat melakukan pengolahan data siswa, wakil kepala 
sekolah dan pertanyaan kuesioner yang ada pada sistem. User kedua adalah siswa yang dapat melakukan login pada sistem dan memilih mata pelajaran yang akan diisi kemudian melakukan pengisian kuesioner. Setelah melakukan pengisian, hasil kuesioner siswa akan dianalisis menggunakan metode QFD sebelum disimpan pada database. User ketiga adalah wakil kepala sekolah yang dapat melakukan login pada sistem untuk melihat hasil kuesioner siswa. Setelah melakukan login wakil kepala sekolah memilih mata pelajaran mana yang akan dilihat hasilnya, hasil yang ditampilkan berupa grafik batang yang dapat dilihat pada Gambar 7. Blok diagram sistem informasi kepuasan belajar mengajar dapat dilihat pada Gambar 5 .

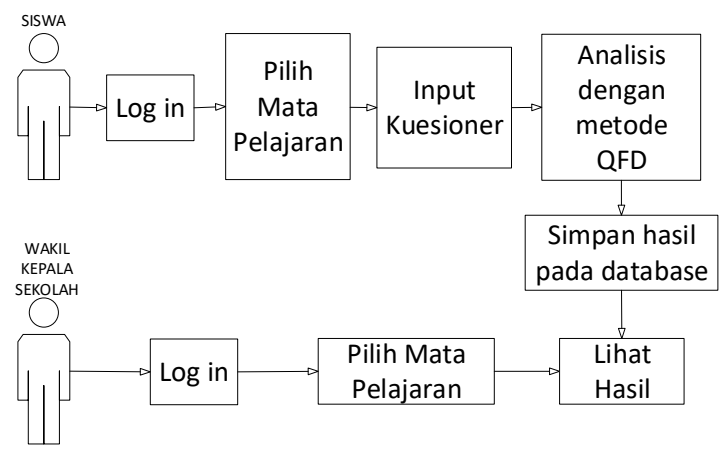

Gambar 5. Blok Diagram pada sistem analisis kepuasan belajar mengajar

\section{Hasil dan Pembahasan}

Pada bab ini, akan menjelaskan implementasi dari perancangan sistem yang telah dijelaskan pada bab sebelumnya, yang terdiri dari implementasi database, implementasi class dan implementasi interface serta pengujian sistem.

\section{A. Implementasi Database Sistem Informasi Analisis Kepuasan Belajar Mengajar}

Database sistem informasi kepuasan belajar mengajar pada SMA Negeri 3 Mataram terdiri dari beberapa tabel yaitu: admin, guru, kasubag, kelas, mapel, mengajar, nilai_interaksi, parameter, pertanyaan, siswa dan status_isi_kuesioner. Database sistem informasi kepuasan belajar mengajar dapat dilihat pada Gambar 6.

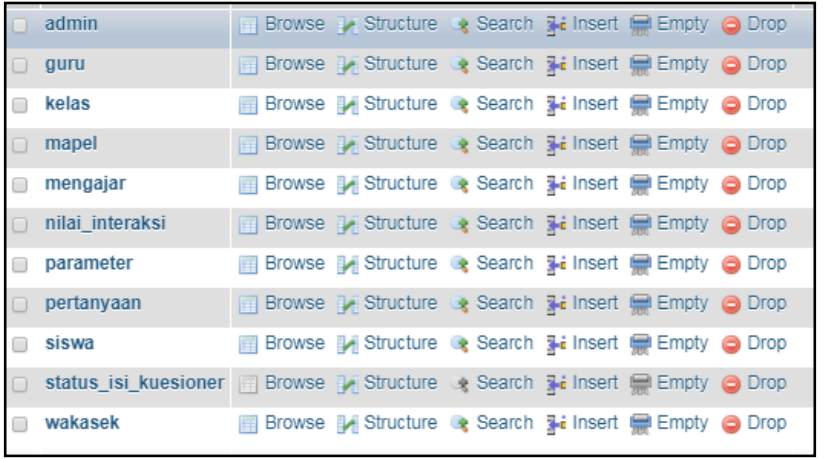

Gambar 6. Database pada sistem analisis kepuasan belajar mengajar

\section{B. Implementasi Class Sistem Informasi Analisis Kepuasan Belajar Mengajar}

Class dibangun berdasarkan konsep MVC (Model, View, Controller) pada frameworkCodelgniter. Classclass pada sistem informasi analisis kepuasan belajar mengajar dijelaskan sebagai berikut:

\section{B.1. Class pada Model}

Class pada model memiliki beberapa model pada Sistem Kepuasan Belajar Mengajar, dimana model tersebut digunakan untuk melakukan query-query database dan kemudian hasil query-query tersebut diproses oleh sistem.

\section{B.2. Class pada Controller}

Class pada controllers berisi Class-class pada controller yang digunakan untuk memproses halaman yang diminta oleh pengguna. Classcontroller menggunakan classmodel untuk mengambil data dari basis data lalu menyiapkan tampilan halaman beserta data tersebut.

\section{Tampilan Aplikasi}

Halaman daftar mata pelajaran digunakan oleh siswa untuk melihat mata pelajaran yang sedang dilaksanakan pada tahun ajar yang sedang berjalan. Siswa dapat mengisi kuesioner dengan menekan tombol isi pada masing-masing mata pelajaran seperti yang dapat dilihat pada Tabel I.

TABEL I. DAFTAR MATA PELAJARAN YANG DIAKSES OLEH SISWA

\begin{tabular}{|l|l|c|}
\hline \multicolumn{1}{|c|}{ Nama Mapel } & \multicolumn{1}{c|}{ Nama Guru } & \multicolumn{1}{c|}{ Aksi } \\
\hline Pend. Agama Islam & Asmawati, S.Ag & $2018 / 2019$ \\
\hline Pend. Agama Hindu & $\begin{array}{l}\text { I Made Putra Suryantara, } \\
\text { S.Pd.H.,M.I.Kom }\end{array}$ & $2018 / 2019$ \\
\hline Antropologi & Novi Sundari Sanusi, S.Pd & $2018 / 2019$ \\
\hline
\end{tabular}


Tabel isi kuesioner digunakan oleh siswa untuk mengisi kuesioner suatu mata pelajaran. Terdapat beberapa atribut dimana siswa memilih nilai persepsi dan ekspektasi pada masing - masing atribut.

TABEL II. ISI KUESIONER YANG DILAKUKAN OLEH SISWA

\begin{tabular}{|c|c|c|c|c|c|c|c|c|c|c|}
\hline \multirow{2}{*}{\begin{tabular}{l}
\multicolumn{1}{c}{ Pertanyaan } \\
$\begin{array}{l}\text { Guru memiliki silabus mata } \\
\text { pelajaran yang diampu }\end{array}$
\end{tabular}} & \multicolumn{5}{|c|}{ Ekspektasi } & \multicolumn{5}{|c|}{ Persepsi } \\
\hline & $\begin{array}{l}1 \\
0\end{array}$ & $0^{2}$ & $3^{3}$ & $\stackrel{4}{0}$ & 5 & $\begin{array}{l}1 \\
0\end{array}$ & $2^{2}$ & $\stackrel{3}{0}$ & $\stackrel{4}{\circ}$ & 5 \\
\hline $\begin{array}{l}\text { Guru menyampaikan } \\
\text { silabus pembelajaran pada } \\
\text { awal pertemuan }\end{array}$ & $\begin{array}{l}1 \\
0\end{array}$ & $\stackrel{2}{0}^{2}$ & ${ }^{3}$ & $\stackrel{4}{0}$ & $\stackrel{5}{0}$ & $\begin{array}{l}1 \\
0\end{array}$ & $\begin{array}{l}2 \\
0\end{array}$ & $\begin{array}{l}3 \\
0\end{array}$ & $\stackrel{4}{0}^{4}$ & ${ }^{5}$ \\
\hline $\begin{array}{l}\text { Guru menguasai materi } \\
\text { pembelajaran }\end{array}$ & $\begin{array}{l}1 \\
0\end{array}$ & $\begin{array}{l}2 \\
0\end{array}$ & $\begin{array}{l}3 \\
0\end{array}$ & $\stackrel{4}{0}$ & $\begin{array}{l}5 \\
0\end{array}$ & $\begin{array}{l}1 \\
0\end{array}$ & $\stackrel{2}{0}$ & 3 & $\begin{array}{l}4 \\
0\end{array}$ & 5 \\
\hline
\end{tabular}

Tabel daftar mata pelajaran dari sisi Wakil Kepala Sekolah digunakan untuk melihat daftar hasil kuesioner mata pelajaran yang diajarkan pada tahun ajar tertentu. Halaman ini dapat dilihat pada Tabel III.

TABEL III. HASIL KUESIONER YANG DIAKSES OLEH WAKIL KEPALA SEKOLAH

\begin{tabular}{|l|l|l|l|l|l|}
\hline No & \multicolumn{1}{|c|}{ Kelas } & $\begin{array}{l}\text { Nama } \\
\text { Mapel }\end{array}$ & Nama Guru & $\begin{array}{l}\text { Tahun } \\
\text { Ajar }\end{array}$ & Aksi \\
\hline 1 & 2. IPA.PILIHAN & $\begin{array}{l}\text { Pend. } \\
\text { Agama } \\
\text { Islam }\end{array}$ & $\begin{array}{l}\text { Kasmiun } \\
\text { S.Ag.M.Pd.I }\end{array}$ & $\begin{array}{l}2018 / \\
2019\end{array}$ & lihat \\
\hline 2 & 2. IPA1 & $\begin{array}{l}\text { Pend. } \\
\text { Agama } \\
\text { Islam }\end{array}$ & $\begin{array}{l}\text { Kasmiun } \\
\text { S.Ag.M.Pd.I }\end{array}$ & $\begin{array}{l}2018 / \\
2019\end{array}$ & lihat \\
\hline
\end{tabular}

Gambar 7 menunjukkan hasil berupa grafik batang dimana grafik ini menunjukkan nilai persentase masing-masing parameter (atribut). Terdapat 26 parameter yang harus ditingkatkan dimana masingmasing parameter memiliki nilai persentase yang digunakan sebagai acuan parameter mana yang harus ditingkatkan. Semakin tinggi nilai persentase dari sebuah parameter maka parameter tersebut menjadi prioritas untuk ditingkatkan. Grafik batang disajikan pada Gambar 7.

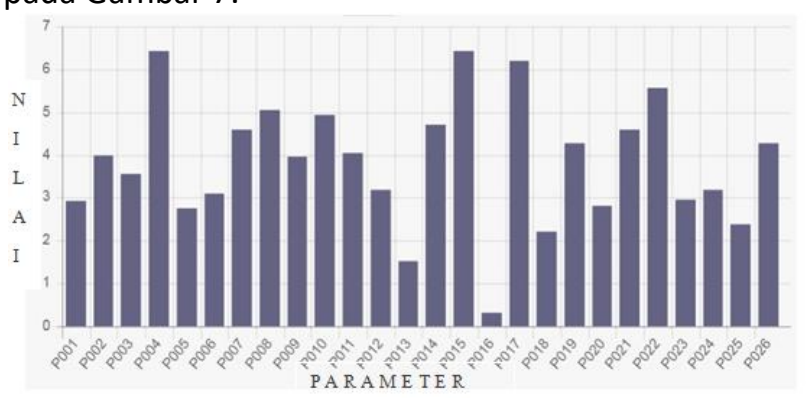

Gambar 7. Halaman hasil analisis Metode Quality Function Deployment oleh wakil Kepala Sekolah(2)
Tabel IV merupakan laporan hasil kuesioner menampilkan rincian dari diagram batang pada Gambar 7. Tabel ini menunjukkan parameter yang menjadi prioritas untuk ditingkatkan pada proses belajar mengajar di SMA Negeri 3 Mataram. Terdapat 3 kolom pada Tabel halaman laporan hasil kuesioner, dimana kolom pertama adalah kode yang memberikan informasi tentang nomor parameter. Kolom kedua adalah parameter, yaitu parameter yang digunakan sebagai acuan untuk meningkatkan proses belajar mengajar. Yang ketiga yaitu persentase, kolom ini berfungsi sebagai pemberi nilai parameter dimana semakin tinggi nilai persentase dari sebuah parameter maka parameter tersebut menjadi prioritas untuk ditingkatkan. Parameter yang harus ditingkatkan dapat dilihat pada Tabel IV.

TABEL IV. HALAMAN LAPORAN HASIL ANALISIS Metode Quality Function DePLOYMENT OLEH WAKIL KePALA SEKOLAH(2)

\begin{tabular}{|c|c|c|}
\hline Kode & Parameter & Persentase \\
\hline P004 & $\begin{array}{l}\text { Guru mengevaluasi materi pada akhir } \\
\text { pertemuan }\end{array}$ & $7.364 \%$ \\
\hline $\mathrm{P} 021$ & $\begin{array}{l}\text { Adanya penambahan waktu pada saat } \\
\text { praktik }\end{array}$ & $5.275 \%$ \\
\hline $\mathrm{P} 022$ & $\begin{array}{l}\text { Guru memberi tahu materi apa saja } \\
\text { yang akan diajarkan }\end{array}$ & $5.116 \%$ \\
\hline $\mathrm{P} 014$ & $\begin{array}{l}\text { Guru harus memiliki pedoman pokok } \\
\text { bahasan yang akan diajarkan }\end{array}$ & $5.108 \%$ \\
\hline P019 & $\begin{array}{l}\text { Guru berinteraksi dengan siswa } \\
\text { selama proses belajar mengajar }\end{array}$ & $5.105 \%$ \\
\hline P008 & $\begin{array}{l}\text { Materi evaluasi sesuai dengan materi } \\
\text { yang diajarkan }\end{array}$ & $4.974 \%$ \\
\hline P007 & $\begin{array}{l}\text { Memberikan nilai keaktifan pada } \\
\text { siswa }\end{array}$ & $4.846 \%$ \\
\hline $\mathrm{P} 015$ & $\begin{array}{l}\text { Guru lebih lugas dalam } \\
\text { menyampaikan materi pelajaran }\end{array}$ & $4.846 \%$ \\
\hline P017 & $\begin{array}{l}\text { Guru memberikan peringatan apabila } \\
\text { siswa melanggar aturan }\end{array}$ & $4.843 \%$ \\
\hline P026 & $\begin{array}{l}\text { Kegiatan praktik mendukung proses } \\
\text { pembelajaran }\end{array}$ & $4.843 \%$ \\
\hline P010 & $\begin{array}{l}\text { Guru mampu memotivasi belajar } \\
\text { siswa }\end{array}$ & $4.719 \%$ \\
\hline $\mathrm{P} 002$ & $\begin{array}{l}\text { Suara guru saat menyampaikan } \\
\text { materi jelas }\end{array}$ & $4.712 \%$ \\
\hline P011 & $\begin{array}{l}\text { Guru membimbing siswa pada saat } \\
\text { pemberian materi berlangsung }\end{array}$ & $4.093 \%$ \\
\hline $\mathrm{P} 012$ & Terdapat buku panduan untuk praktik & $3.382 \%$ \\
\hline P009 & $\begin{array}{l}\text { Cara guru menyampaikan materi } \\
\text { mudah dipahami }\end{array}$ & $3.28 \%$ \\
\hline $\mathrm{P} 005$ & Guru mengulas kembali hasil ulangan & $3.183 \%$ \\
\hline $\mathrm{P} 024$ & $\begin{array}{l}\text { Guru memiliki lebih dari satu } \\
\text { referensi dalam mengajar }\end{array}$ & $3.183 \%$ \\
\hline $\mathrm{P} 001$ & Cara mengajar guru lebih interaktif & $3.104 \%$ \\
\hline $\mathrm{P} 023$ & $\begin{array}{l}\text { Guru membimbing siswa saat praktik } \\
\text { berlangsung }\end{array}$ & $3.02 \%$ \\
\hline P006 & $\begin{array}{l}\text { Materi yang disampaikan guru } \\
\text { berurutan }\end{array}$ & $2.842 \%$ \\
\hline P020 & $\begin{array}{l}\text { Pokok bahasan yang disampaikan } \\
\text { guru dapat diterima dan dimengerti }\end{array}$ & $2.763 \%$ \\
\hline P025 & $\begin{array}{l}\text { Adanya tanya jawab selama proses } \\
\text { belajar mengajar berlangsung }\end{array}$ & $2.763 \%$ \\
\hline $\mathrm{P} 003$ & Cara menjelaskan guru lebih detail & $2.692 \%$ \\
\hline
\end{tabular}




\begin{tabular}{|c|l|c|}
\hline P018 & $\begin{array}{l}\text { Cara guru menyampaikan materi } \\
\text { tidak monoton }\end{array}$ & $1.822 \%$ \\
\hline P013 & $\begin{array}{l}\text { Guru mengembalikan hasil tugas / } \\
\text { ulangan siswa }\end{array}$ & $1.768 \%$ \\
\hline P016 & $\begin{array}{l}\text { Guru memberikan penilaian secara } \\
\text { objektif dan transparan pada siswa }\end{array}$ & $0.354 \%$ \\
\hline
\end{tabular}

\section{Hasil Pengujian dan Pembahasan}

\section{D1. Pengujian black box}

Pengujian black box digunakan untuk melihat keberhasilan fitur-fitur yang ada dalam aplikasi berjalan sesuai dengan fungsinya. Setelah diuji ke-validasiannya semua fungsipada sistem ini telah berjalan dan valid. Berdasarkan hasil pengujian black box yang telah dilakukan, fungsi-fungsi yang ada pada sistem informasi kepuasan belajar mengajar telah berjalan dengan baik sesuai dengan fungsinya masing masing.

D2. Pengujian Mean Opinion Score (MOS) Pengujian ini dilakukan oleh 3 pengguna yang akan menggunakan sistem yaitu siswa, admin, dan wakil kepala sekolah. Pengujian akan melibatkan 150 siswa, 1 wakil kepala sekolah dan1 admin. Pengujian dilakukan dengan menjelaskan sistem kepada pengguna, kemudian memberikan pengguna kesempatan untuk mencoba sistem secara langsung agar dapat memberikan penilaian terhadap sistem melalui pengisian kuesioner. Tabel $\mathrm{V}$ merupakan tabel skala likert yang digunakan sebagai penilaian pada tabel VI. Tabel VI merupakan hasil rata-rata pengujian sistem dari semua pengguna.

TABEL V.TABEL SKALA LIKERT

\begin{tabular}{|c|c|c|c|}
\hline Mos & Keterangan & Bobot Nilai & Kelompok \\
\hline SS & Sangat Setuju & 7 & Good \\
\hline S & Setuju & 6 & Good \\
\hline AS & Agak Setuju & 5 & Good \\
\hline $\mathrm{N}$ & Netral & 4 & Neutral \\
\hline ATS & Agak Tidak Setuju & 3 & Bad \\
\hline TS & Tidak Setuju & 2 & Bad \\
\hline STS & $\begin{array}{c}\text { Sangat Tidak } \\
\text { Setuju }\end{array}$ & 1 & Bad \\
\hline
\end{tabular}

TABEL VI. HASIL KUESIONER OLEH WAKIL KEPALA SEKOLAH, SISWA DAN ADMIN

\begin{tabular}{|c|c|c|c|c|c|c|c|c|c|}
\hline $\begin{array}{l}\mathbf{N} \\
\mathbf{0}\end{array}$ & $\begin{array}{l}\text { Pertan } \\
\text { yaan }\end{array}$ & $\begin{array}{l}\text { SS } \\
(7)\end{array}$ & $\begin{array}{ll}S \\
(6)\end{array}$ & $\begin{array}{l}\mathbf{A S} \\
(\mathbf{5}) \\
\end{array}$ & $\begin{array}{l}\mathbf{N} \\
(4)\end{array}$ & $\begin{array}{l}\text { ATS } \\
\text { (3) }\end{array}$ & $\begin{array}{l}\text { TS } \\
(2)\end{array}$ & $\begin{array}{l}\text { STS } \\
(1)\end{array}$ & Ma \\
\hline 1 & $\begin{array}{l}\text { Pertan } \\
\text { yaan } 1\end{array}$ & 25 & 7 & & & & & & $\begin{array}{l}7,2 \\
3\end{array}$ \\
\hline 2 & $\begin{array}{l}\text { Pertan } \\
\text { yaan } 2 \\
\end{array}$ & 15 & 11 & 5 & 1 & & & & $\begin{array}{l}6,6 \\
7 \\
\end{array}$ \\
\hline 3 & $\begin{array}{l}\text { Pertan } \\
\text { yaan } 3 \\
\end{array}$ & 13 & 11 & 3 & 3 & 2 & & & $\begin{array}{l}6,3 \\
3 \\
\end{array}$ \\
\hline 4 & $\begin{array}{l}\text { Pertan } \\
\text { yaan } 4\end{array}$ & 13 & 13 & 2 & 3 & & & & $\begin{array}{l}6,3 \\
7 \\
\end{array}$ \\
\hline 5 & $\begin{array}{l}\text { Pertan } \\
\text { yaan } 5\end{array}$ & 15 & 9 & 7 & & & & & $\begin{array}{l}6,4 \\
7 \\
\end{array}$ \\
\hline 6 & $\begin{array}{l}\text { Pertan } \\
\text { yaan } 6\end{array}$ & 18 & 14 & & & & & & $\begin{array}{l}7,0 \\
0 \\
\end{array}$ \\
\hline 7 & $\begin{array}{l}\text { Pertan } \\
\text { yaan } 7\end{array}$ & 13 & 4 & 7 & 4 & 4 & & & $\begin{array}{l}5,9 \\
3 \\
\end{array}$ \\
\hline 8 & $\begin{array}{l}\text { Pertan } \\
\text { yaan } 8\end{array}$ & 25 & 5 & 2 & & & & & $\begin{array}{l}7,1 \\
7 \\
\end{array}$ \\
\hline \multicolumn{9}{|c|}{ MOS (Mean Opinion Score) } & $\begin{array}{l}6,6 \\
5 \\
\end{array}$ \\
\hline
\end{tabular}

Untuk menghitung total skor rata-rata jawaban dapat menggunakan persamaan 9 sebagai berikut:

$$
(M a)=\frac{\sum p i}{n}
$$

\section{Dengan :}

$\mathrm{Ma}$

pertanyaan

pi pertanyaan

$\mathrm{n}$

:Rata-rata skor setiap atribut

:jumlah skor kali bobot setiap atribut

.jumlah responden

Persamaan 10 digunakan untuk mencari Mean Opinion Score atau mencari total skor rata-rata yang diberikan responden pada seluruh atribut pertanyaan.

Dengan:

$$
M O S=\frac{\sum_{i=1}^{k} M e a n p i}{k}
$$

MOS : total skor rata-rata seluruh atribut pertanyaan

k

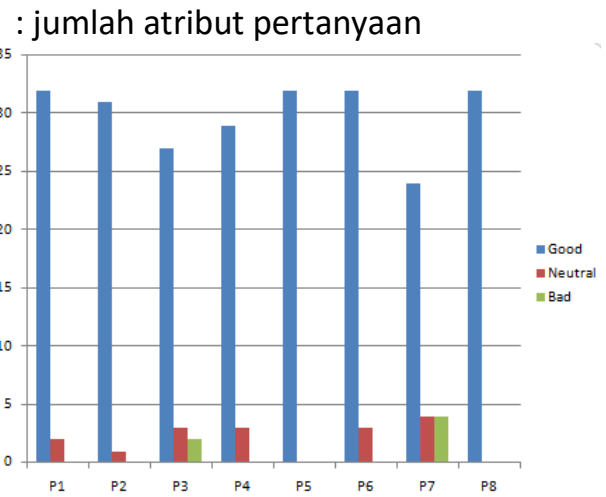

Gambar 8. Grafik respon jawaban kuesioner Wakil Kepala Sekolah, Siswa dan Admin berdasarkan tingkat kategori Good, Neutral dan Bad 
Persentase Jawaban Kuesioner. Gambar 10 merupakan grafik batang yang menggambarkan persentase jawaban dari pengisian kuesioner oleh 30 siswa, 1 admin dan 1 wakil kepala sekolah berdasarkan tingkat kategori Good, Neutral dan Bad.

TABEL VII. Persentase RATA - RATA Jawaban KUESIONER

\begin{tabular}{|c|c|}
\hline Kategori & Persentase \\
\hline Good & $91,6 \%$ \\
\hline Neutral & $6,1 \%$ \\
\hline Bad & $2,3 \%$ \\
\hline
\end{tabular}

Berdasarkan dari pengujian MOS yang dilakukan oleh siswa, Wakil Kepala Sekolah dan admin persentase rata - rata jawaban dengan kategori Good $=91,6 \%$, Neutral=6,1\%, Bad=2,3\% maka sistem informasi kepuasan belajar mengajar disimpulkan telah berjalan dengan baik dengan hasil uji MOS $\geq 5.00$.

\section{Kesimpulan dan Saran}

\subsection{Kesimpulan}

Berdasarkan hasil pembahasan dan pengujian sistem yang dibuat, maka dapat diambil kesimpulan sebagai berikut

1. Dengan adanya sistem informasi kepuasan belajar mengajar ini memudahkan pihak sekolah untuk mengevaluasi proses belajar mengajar di sekolah dengan cara yang lebih efisien dan akurat.

2. Hasil kuesioner dapat dilihat oleh wakil kepala sekolah guna mengevaluasi hasil kuesioner siswa terhadap proses belajar mengajar.

3. Penerapan metode Quality Function Deployment pada sistem kepuasan belajar mengajar pada SMA Negeri 3 Mataram menghasilkan kesimpulan berupa urutan prioritas yang dapat ditingkatkan oleh pihak sekolah.

\subsection{Saran}

Adapun saran yang disampaikan untuk pengembangan lebih lanjut Sistem Informasi Kepuasan Belajar Mengajar (SIKBM) ini adalah :

1. Diharapkan agar sekolah memiliki Sistem Informasi Akademik agar pengaksesan data siswa dapat lebih memudahkan admin dalam penginputan data siswa.

2. Untuk mendapatkan hasil yang maksimal, siswa diwajibkan untuk mengisi kuesioner setiap sebelum kenaikan kelas diikuti sebagai syarat rapor dapat dibagikan setelah pengisian kuesioner selesai.

3. Hasil akhir pada metode QFD menampilkan urutan prioritas yang harus ditingkatkan sekolah dimana urutan tersebut hanya berdasarkan satu mata pelajaran oleh satu guru saja.

\section{UCAPAN TERIMA KASIH}

Ucapan terima kasih dapat diberikan kepada penyandang dana penelitian dan orang yang memberikan kontribusi ilmiah pada penelitian namun bukan merupakan penulis artikel ini.

\section{DAfTAR PUSTAKa}

[1] A. W. Wicaksono, "Penerapan Metode Quality Function Deployment pada Rencana Pengembangan Sekolah di SMKN 2 Yogyakarta," vol. 1, 2013.

[2] D. S. Purwani, "Penerapan Metode Quality Function Deployment pada Unit Usaha di SMKN 2 Yogyakarta," 2013.

[3] Hartanto, "Analisa Kualitas Pelayanan Perpustakaan Perguruan Tinggi dengan Metode Qualitu Function Deployment," 2008.

[4] Saifullah, "Analisa Kepuasan Layanan Administrasi Akademik berbasis Importance Performance Analysis dengan kasus pada Fakultas Teknik Universitas Mataram," 2016.

[5] Sukmadinata, Implementasi Life Skill dalam KTSP. Bandung: CV. Mughni Sejahtera., 2012.

[6] Sugiyono, Metode Penelitian Pendidikan (Pendekatan Kuantitatif, Kualitatif dan R\&D). Bandung: Alfabeta, 2006.

[7] Arikunto, Dasar-dasar Evaluasi Pendidikan. Jakarta: Buku Aksara, 2002.

[8] M. N. Nasution, Manajemen Mutu Terpadu (Quality Function Deployment). Jakarta: Penerbit Ghalia Indonesia, 2001.

[9] M. Xie, Advanced QFD Application. Winconsin: ASQ Quality Press.

[10] I. J. Grady Booch, James Rumbaugh, The Unified Modeling Languages Reference Manual. Massachusetts: Addison Wesley, 1998. 